\title{
Jornalistas: um perfil socioprofissional em mudança
}

Joaquim Fidalgo*

Em meados do ano de 2002, iniciou-se em Portugal, no âmbito do Sindicato dos Jornalistas, o processo de constituição de um novo núcleo: o Núcleo Sindical dos Jornalistas "On-line". Explicando a sua necessidade face a novas realidades do universo mediático, um dos promotores da iniciativa alertava para a falta de legislação específica neste domínio e dizia assim: "Não existe nada que permita regular o sector, ao nível, por exemplo, do direito de resposta ou da distinção entre produto jornalístico e produto promocional" [itálico meu] ${ }^{1}$. O mesmo jornalista insistia que "a definição do que é um trabalho jornalístico no âmbito de uma actividade 'on-line' é mesmo fundamental para a credibilização do jornalismo digital”, deixando subentender a particular dificuldade da tarefa face à "diversidade de funções exercidas pelos profissionais empregues em órgãos de comunicação social digitais"2 [itálicos meus].

Este é, afinal, apenas mais um exemplo - particularmente visível e particularmente actual, não só em Portugal como noutras latitudes - de como à tentativa de resolução de velhas interrogações sobre a identidade dos jornalistas e a especificidade da sua função (Albert, 1970; Delporte, 1999; Mathien, 1995; Neveu, 2001; Ruellan, 1997; Traquina, 2002) se acrescentam, hoje, novos dilemas, novas indefinições e novos desafios. Ou, no mínimo, se reforçam as dúvidas e ambiguidades que, de algum modo, sempre foram marcando a tentativa de construção de um espaço profissional autónomo e claramente delimitado por parte dos jornalistas, seja no plano geral da sua relação com a sociedade, seja no domínio específico da comunicação.

Acresce que esta não é uma questão que possa reduzir-se a uma espécie de reivindicação corporativa ou à vaidade de afirmação de uma especificidade e de um "saber exclusivo" - com o que tal significaria de utilidade, para não dizer de carácter até imprescindível ou mesmo insubstituível da profissão de jornalista. Esta indefinição persistente, esta mistura de papéis, esta diluição de fronteiras entre ofícios no campo da comunicação (a que parece corresponder também uma diluição, ou uma confu-

\footnotetext{
* Jornalista, ex-Provedor do Leitor do jornal Público, professor convidado no Departamento de Ciências da Comunicação/ Instituto de Ciências Sociais da Universidade do Minho (jfidalgo@ics.uminho.pt).

${ }^{1}$ Ver "Precariedade dos jornalistas ‘on-line' aumenta em Portugal”, in Público, ed. 29 de Agosto de 2002, p. 33.

${ }^{2}$ Ibidem.
} 
são, das responsabilidades específicas de cada um) têm repercussões que extravasam o âmbito individual e colectivo dos jornalistas, afectando o modo como o seu trabalho é visto e recebido pela sociedade a que se destina. Afectando, portanto, o papel da informação (e a sua percepção) na esfera pública.

A uma crise de legitimidade e a uma crise de identidade que são recorrentes na reflexão que os jornalistas fazem sobre si próprios soma-se, assim, uma crise de credibilidade e de confiança que é patente no modo cada vez mais céptico como os cidadãos encaram e digerem a informação que recebem, bem como o modo como classificam (ou julgam) os actores mais visíveis do processo informativo. Uma sondagem realizada em 2002 pela BBC para avaliar quais as profissões mais e menos respeitadas pelo público britânico colocava os jornalistas num desconfortável 88. lugar (a lista tinha 92 profissões), apenas à frente de advogados, ministros, agentes imobiliários e deputados ${ }^{3}$. Não deixa de ser curioso notar que os jornalistas são colocados, em termos de respeito público, ao nível (tradicionalmente bastante baixo) dos políticos, e muito longe dos profissionais que prestam serviços mais palpáveis à comunidade, como os médicos, os enfermeiros, os professores ou os bombeiros - as profissões que ocupavam os primeiros lugares nesta sondagem da BBC...

Passemos em revista, rapidamente, alguns dados sobre a evolução recente deste grupo profissional em Portugal.

\section{Os jornalistas são cada vez mais}

Embora as tendências mais recentes apontem para uma clara recessão no mercado de trabalho dos jornalistas, as últimas duas décadas revelaram uma forte taxa de crescimento quanto ao número de profissionais em Portugal (ver Gráfico 1).

Gráfico 1 - Evolução do número total de jornalistas

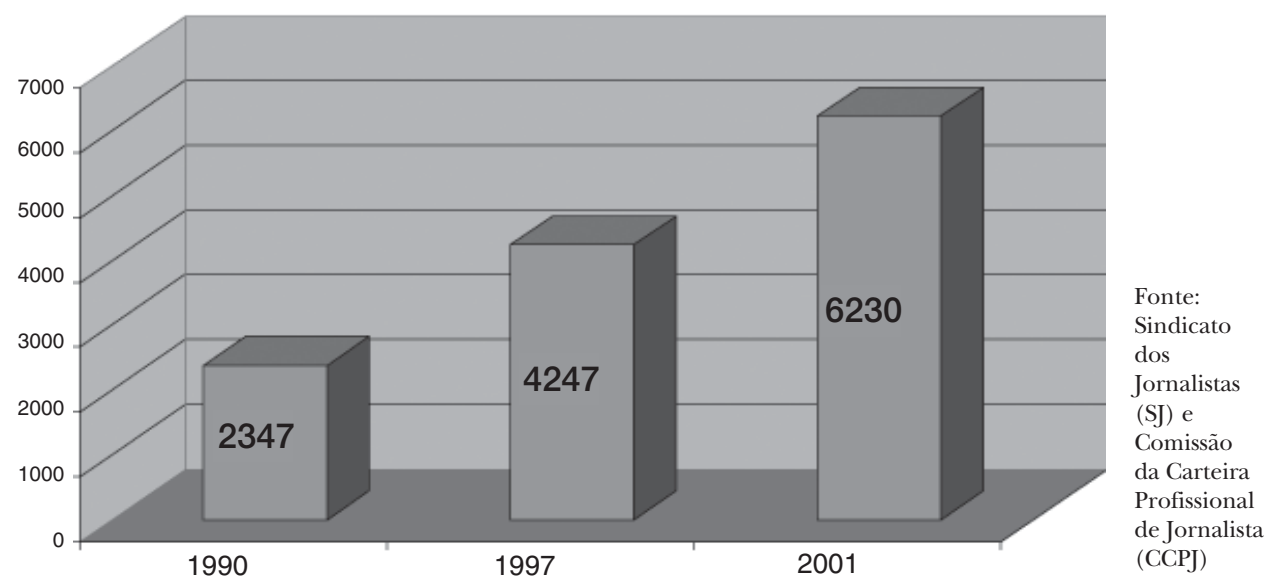

${ }^{3}$ Ver The Guardian, edição de 29 de Maio de 2002 (consultada a versão “on-line”). 
Em vinte anos, quase triplicou o número de jornalistas profissionais em funções activas, tendo os dois últimos grandes momentos de expansão deste mercado sido o início de funcionamento dos canais privados de televisão (1992) e o desenvolvimento de edições electrónicas dos jornais (processo iniciado em 1995 pelo Jornal de Notícias e pelo Público), cada vez mais autonomizadas deles e alargando o seu raio de acção a novos serviços informativos.

O número de 6230 profissionais em actividade no país, referido ao biénio 2000-01, inclui apenas os titulares de carteira profissional de jornalista (5 794) e os titulares de título provisório de jornalista estagiário (436). Se lhes acrescentarmos os detentores de outro tipo de títulos igualmente certificados pela Comissão da Carteira Profissional de Jornalista (CCPJ) - equiparados a jornalistas (289), correspondentes locais (6), correspondentes estrangeiros (50), colaboradores regionais (107), colaboradores especializados (11), colaboradores nas comunidades portuguesas (4) -, o número global sobe para 6697.

Naturalmente, haveria ainda a considerar, para um levantamento mais rigoroso da quantidade de pessoas envolvidas na área informativa dos meios de Comunicação Social, uma cifra razoável (mas não contabilizada, e dificilmente contabilizável, por razões óbvias) de colaboradores em "full" ou "part-time" que, sem preencherem os requisitos de acesso a um título profissional ou sem se preocuparem em o obter, asseguram o funcionamento de muitos jornais e rádios de âmbito local ou regional.

Há indícios vários de que esta tendência expansionista já entrou em desaceleração, senão mesmo em regressão. Ao longo dos dois últimos anos (2002 e 2003), sucederam-se as notícias sobre reduções de pessoal nas redacções de muitos órgãos de comunicação bem conhecidos (Público, Diário de Notícias, Expresso, Jornal de Notícias, TSF, RTP, SIC), alguns deles com inquestionável solidez económico-financeira e até com lucros declarados nos últimos anos. Por um lado, a retracção da publicidade já verificada em 2001 e continuada em 2002, sem grandes perspectivas de retoma, afectou a rentabilidade das empresas - convém não esquecer que, num mercado tão exíguo como o português, em que as tiragens dos maiores jornais só excepcionalmente atingem a cifra dos cem mil exemplares ${ }^{4}$, é percentualmente muito elevada a dependência das receitas publicitárias. Por outro lado, as extensões electrónicas dos media tradicionais (sejam os da imprensa escrita, sejam os da televisão) estão claramente em retracção, depois do grande entusiasmo dos primeiros passos, pois permanecem adiadas (porventura sine die) as perspectivas de rentabilização de um serviço que, embora cada vez mais utilizado pelos portugueses, continua a ser distribuído gratuitamente em grande parte dos casos e a não atrair publicidade que pague sequer os investimentos em tecnologia ou em pessoal.

\footnotetext{
${ }^{4}$ Os dados da Associação Portuguesa para o Controlo de Tiragens (APCT) relativos ao primeiro semestre de 2003 confirmam que apenas dois diários superam os cem mil exemplares de circulação paga: o Correio da Manhã (média de 109758 exemplares) e o Jornal de Notícias (105 496). Quanto aos semanários de informação geral, no mesmo período, apenas dois títulos ultrapassam aquela cifra: o Expresso (média de 136670 exemplares) e a Visão (107 084).
} 


\section{Há cada vez mais mulheres jornalistas}

No que toca à distribuição por género, é patente uma presença cada vez mais forte das mulheres no universo do jornalismo profissional em Portugal. Se o número de jornalistas homens pouco mais que duplicou entre 1990 e 2001 (de 1772 para 3 867), o de jornalistas mulheres quase quadruplicou (de 602 para 2 363), aproximando-as em termos percentuais: eram 25,4 por cento do total há 20 anos, constituem hoje 38 por cento do universo dos jornalistas (ver Gráfico 2).

Gráfico 2 - Percentagem de jornalistas por género

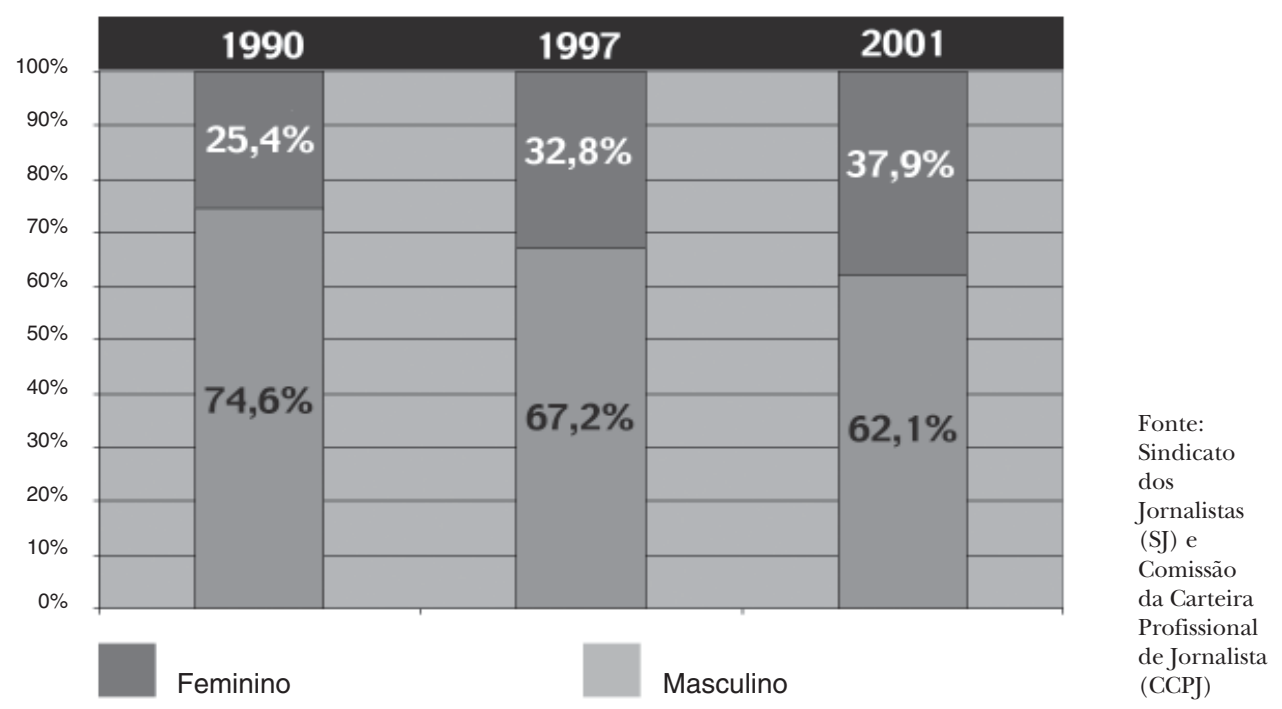

Esta tendência é particularmente visível, como se imaginaria, nos escalões mais jovens da profissão. De entre os titulares de carteira profissional com menos de 30 anos, o número de mulheres é já mais elevado do que o de homens (798 contra 649); a mesma realidade se verifica nos detentores de título provisório de jornalista estagiário, onde existem 222 mulheres e 214 homens.

Questão diferente será saber até que ponto estas alterações quantitativas (que deverão prosseguir e até reforçar-se, a avaliar pela esmagadora preponderância do género feminino entre os estudantes de cursos das áreas da Comunicação nas escolas portuguesas) significam também alguma alteração qualitativa, alargando o leque de perspectivas e pontos de vista na abordagem dos acontecimentos (Rieffel, 2001), e com isso enriquecendo o panorama de um espaço público tradicionalmente muito marcado pela preponderância do "masculino". Um dado parece claro: a entrada de mais mulheres na profissão não tem tido uma correspondência proporcional (talvez por se tratar de um processo ainda recente, mas talvez não só...) na ocupação de cargos de chefia, onde os homens ainda são a regra. Uma amostra disso mesmo pode verificar-se na distribuição dos jornalistas por género no conjunto de três dos mais importantes diários portugue- 
ses: Jornal de Notícias, Diário de Notícias e Público - cujas equipas directivas são, aliás, constituídas exclusivamente por homens. Dados por mim recolhidos em 2001, no âmbito de um outro trabalho de pesquisa, revelavam que, no conjunto das três redacções daqueles diários, havia 64 por cento de jornalistas do género masculino e 36 por cento do género feminino. No entanto, olhando apenas para as posições de chefia, veríamos que 84 por cento dos cargos eram ocupados por jornalistas-homens, enquanto apenas 16 por cento eram ocupados por jornalistas-mulheres.

\section{Há cada vez mais jovens jornalistas}

Acompanhando esta tendência de maior "feminização" do grupo profissional dos jornalistas portugueses, também a pirâmide etária tem evoluído no sentido de uma notória "juvenilização". O número de jornalistas com idade inferior a 30 anos mais do que triplicou entre 1990 e 2001 (de 556 para 1818 profissionais), enquanto o grupo dos mais velhos, com idade acima dos 45 anos, apenas duplicou (de 709 para 1443 profissionais). Como resultado, a presença percentual dos escalões mais jovens no universo do grupo profissional reforçou-se claramente: em 20 anos, passou de 23,4 por cento para 29,2 por cento do total (ver Gráfico 3).

Olhando em pormenor para os dados relativos a 2001, verificamos que o subgrupo etário mais numeroso é o dos jornalistas com idade entre os 26 e os 30 anos - 1504 profissionais -, logo seguido do subgrupo com idades entre os 31 e os 35 anos - 1369 profissionais - e do subgrupo com idades entre os 36 e os 40 anos - 1001 profissionais. É, portanto, uma profissão marcadamente jovem, sobretudo como resultado da sua forte expansão em anos muito recentes.

Gráfico 3 - Percentagem de jornalistas por níveis etários

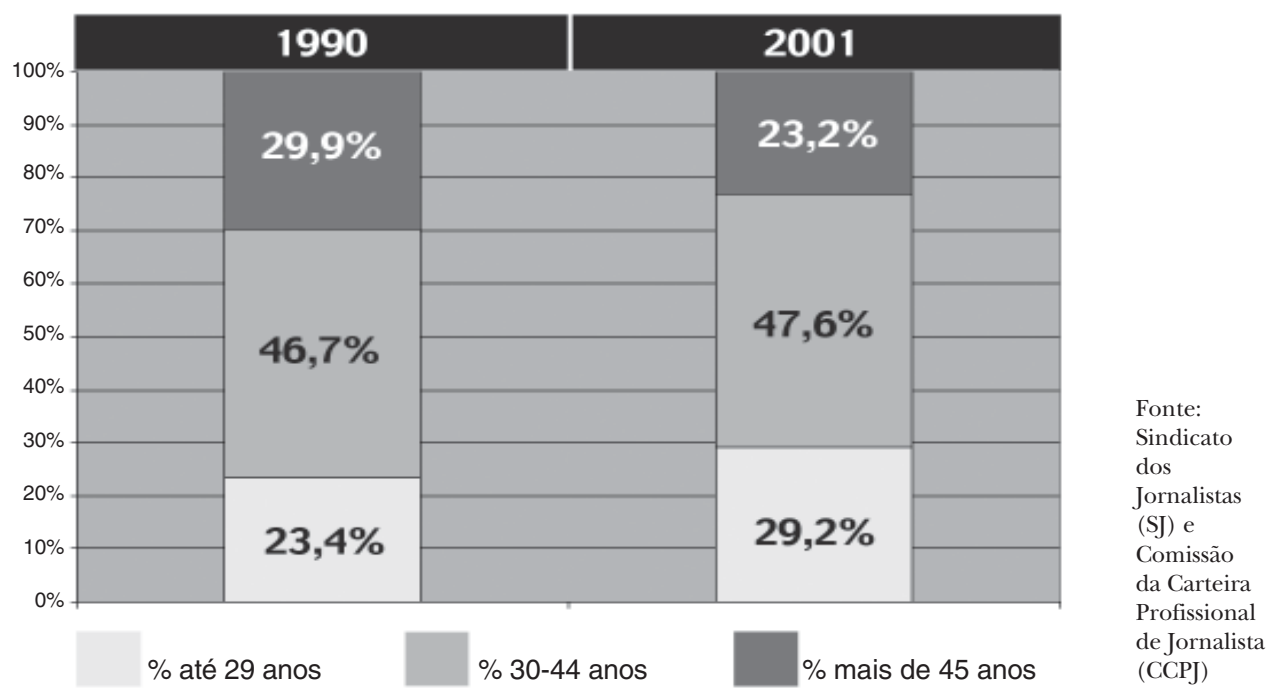


É legítimo admitir que esta tendência trouxe alguma frescura e novas sensibilidades (quer temáticas, quer formais) a uma profissão frequentemente olhada como envelhecida, instalada e até sorumbática. Não obstante, tratando-se de um ofício onde os "saberes de acção" (Barbier, 1996) têm uma importância muito particular e onde o acumular de experiência em contacto directo com a cultura profissional do grupo é especialmente relevante para a formação dos jornalistas, a presença de muitos jovens nas redacções também tem criado novos problemas.

Sabendo-se, como se sabe, que há uma curiosa tendência para entregar aos mais jovens a maioria dos trabalhos "de campo" (sobretudo a reportagem), ficando-se os mais experientes pelo trabalho de retaguarda, sentados à secretária, somos por vezes confrontados com importantes insuficiências profissionais - das quais serão, talvez, menos culpados os jovens jornalistas que tentam dar o seu melhor em situações complexas, e mais os velhos chefes que lhes faltam no imprescindível enquadramento. Por exemplo, "aguentar" um directo em televisão durante minutos e minutos, em cenários por vezes de grande complexidade informativa e de grande impacto emocional (como são acidentes graves, catástrofes naturais, tragédias envolvendo mortos e feridos), não é fácil para qualquer jornalista, e muito menos para quem tenha acabado de chegar ao métier. Ora, em Portugal, com muita frequência são os mais jovens que são lançados para estes tremendos desafios, quando seria da mais elementar prudência reservá-los para profissionais experientes.

Por outro lado, uma certa mitificação de uma maneira "jovem" e "inovadora" de estar no jornalismo, tendo embora inegáveis virtualidades, acaba por conduzir a projectos de grande fragilidade quando não é temperado com algum alicerce de experiência e calo profissional. As experiências ainda recentes, em Portugal, de duas pequenas estações de televisão por cabo muito "modernas" e muito "jovens" - uma (o CNL - Canal de Notícias de Lisboa) totalmente falhada e entretanto reconvertida, outra (a NTV - Televisão do Norte) quase morta à nascença mas agora em recuperação, depois de reorientado o projecto primitivo - aí estão para o mostrar e para, de algum modo, nos deixar o alerta.

\section{Há cada vez mais jornalistas com formação académica específica}

Num inquérito que fiz, em 2001, nas redacções de três dos principais diários portugueses (Jornal de Notícias, Diário de Notícias e Público), e com base numa amostra correspondente a mais de metade dos seus jornalistas ${ }^{5}$, pude constatar que cerca de 50 por cento deles referiam ter alguma formação académica específica nos domínios das Ciências da Comunicação, mesmo que em diversos casos se tratasse de cursos incompletos. Para um país com uma tradição recentíssima no que toca à criação de cursos superiores de Comunicação e de Jornalismo ${ }^{6}$, é uma percentagem muito elevada e até surpreen-

\footnotetext{
${ }^{5}$ Foram recebidas 252 respostas, num total de 457 inquéritos enviados, o que significa uma taxa de respostas da ordem dos 55 por cento. O inquérito abordava matérias relacionadas com o Provedor do Leitor mas foi aproveitado também para recolher alguns elementos que permitam caracterizar melhor, a partir de uma amostra significativa, os jornalistas portugueses na actualidade.

${ }^{6}$ O primeiro destes cursos foi criado apenas em 1978, na Faculdade de Ciências Sociais e Humanas da Universidade Nova de Lisboa, e a maioria dos restantes surgiu nos últimos 20 anos.
} 
dente - independentemente de dever ressalvar-se que estes dados correspondem a uma amostra, logo falível, e se reportam apenas a três jornais portugueses (dois quais dois diários claramente "de referência") que talvez não devam tomar-se como a imagem média da Comunicação Social portuguesa actual.

O certo é que, embora continue a não ser exigido qualquer diploma de estudos superiores em domínos das Ciências da Comunicação para aceder à carreira profissional de jornalista, nos anos mais recentes pode dizer-se que a quase totalidade de novos jornalistas tem sido recrutada entre os diplomados do sector ${ }^{7}$. Sucede isto, na prática, por aquilo a que chamaria mecanismos informais de selecção e recrutamento.

Excluindo casos pontuais de lançamento de novos órgãos de comunicação, em que se procede a concursos públicos para a contratação de novos (ou candidatos a) jornalistas, as contratações actualmente feitas pelos media decorrem quase sempre de estágios profissionalizantes. Muitos órgãos de comunicação portugueses recebem, regularmente, licenciados ou finalistas de cursos superiores de Jornalismo ou Comunicação Social, seja por força de protocolos firmados com as escolas - tendo em vista a concessão de um estágio curricular, considerado parte do curso -, seja por sua livre iniciativa. Há mesmo, aqui e ali, algumas queixas de aproveitamento excessivo, por parte de alguns media, de levas sucessivas de estagiários, que se vão menos formando e mais usando como mão-de-obra gratuita durante três ou seis meses, com garantia de uma permanente renovação, tal a pressão da procura...

$\mathrm{Na}$ prática, os jornais, rádios e televisões acabam por testar os estagiários que recebem e, quando precisam de alargar os seus quadros, recorrem naturalmente a jovens candidatos à profissão que eles já conheceram, que já integraram na cultura específica do seu projecto editorial e de que podem seleccionar os melhores. Assim, por este mecanismo do estágio, as novas contratações acabam por ser feitas (com evidentes vantagens para os media) quase exclusivamente entre licenciados da especialidade. A lei não obriga a tal em Portugal - e será difícil que lá chegue nos tempos mais próximos, dada a insistência do grupo profissional dos jornalistas nas vantagens de manter o carácter aberto desta profissão -, mas as condições concretas e o costume generalizado acabam por conduzir a esse resultado. Daí que, entre os jovens jornalistas portugueses, hoje praticamente não se encontre um só que não tenha feito estudos superiores nesta área.

\section{Há cada vez melhor jornalismo?}

Descrita rapidamente a situação, em termos de alguns novos ventos que sopram na configuração concreta deste grupo profissional em Portugal, seria então de fazer a pergunta óbvia:

Há hoje mais jornalistas, há mais jornalistas jovens, há um grupo profissional mais equilibrado em termos de género, há mais jornalistas (novos e velhos) com formação científica especializada de nível superior - e disso decorre, então, que há melhores jornalistas, que há melhor jornalismo?

\footnotetext{
${ }^{7} \mathrm{E}$ há centenas de novos diplomados em cada ano, pois só no ensino público (universitário e politécnico) entram anualmente, nos cursos mais directamente ligados à Comunicação Social e ao Jornalismo, cerca de mil alunos.
} 
A resposta, naturalmente, não é fácil.

Desde logo, não deve esquecer-se que a qualidade do jornalismo que se faz depende de condições inerentes aos jornalistas, mas depende tanto ou mais de condições que lhes são exteriores - as do contexto empresarial em que a actividade é exercida, as do sistema mediático com as suas lógicas particulares, as do mercado, as do todo social. E se podemos dizer que, hoje em dia, às redacções chegam jovens profissionais mais bem preparados em termos culturais, científicos e técnicos, não é menos verdade que os espera um terreno mais movediço do que outrora, mais indefinido, mais volúvel, mais precário, mas simultaneamente mais pressionante, mais competitivo, mais exigente.

As mudanças e os desafios mais salientes situam-se em múltiplos domínios, de que salientaria quatro: a tecnologia, a empresa jornalística, o mercado (mercado em geral e mercado dos media em particular) e o grupo profissional dos jornalistas.

\section{a) A tecnologia}

Os desenvolvimentos tecnológicos da última década (digital, Internet, acessibilidade e facilidade de comunicações, portabilidade de equipamentos, convergência e integração de suportes comunicativos), ao mesmo tempo que abriram muitas e novas possibilidades ao trabalho dos jornalistas, também redefiniram as suas competências profissionais (Neveu, 2001) e diluíram o seu papel como elemento imprescindível no fluxo de informação entre as fontes primárias e os cidadãos. Desapareceram muitos dos constrangimentos de espaço e de tempo que implicavam obrigatoriamente a existência de mediadores especializados para nos irem contando o que se passa no mundo: hoje proliferam muitos outros mediadores que nada têm a ver com o jornalismo e, em não poucas circunstâncias, é possível aceder directamente à informação em bruto, sem quaisquer mediações.

Mesmo no campo da informação mediatizada, a sacralização do directo televisivo, enroupado na ilusão de que é possível, enfim, mostrar a realidade tal qual ela é sem passar por supostos filtros deformantes, acentuou as dúvidas sobre a relevância do jornalismo - ou, para sermos mais precisos, de um certo tipo de jornalismo. Dito de outro modo, reforçou a urgência de se repensar o exercício desta actividade no novo contexto global, provavelmente redefinindo-se o seu papel e descobrindo-se fórmulas mais eficazes de cumprir a finalidade essencial do jornalismo: não tanto a transmissão de informação mas a "transformação da informação em conhecimento" (Aguinaga, 2001), ou o "dar sentido ao mundo que nos rodeia” (Delforce, 1996: 18), com o que isso significa de investigação, de elaboração, de contextualização, de interpretação.

\section{b) A empresa}

Desenvolvido num contexto empresarial e submetido aos seus naturais constrangimentos económicos, organizacionais e laborais, o jornalismo que hoje se faz, ou que se pode fazer, sofre das contingências de um tecido particularmente frágil como é o português neste domínio. Apesar dos significativos movimentos de concentração das empresas de media em grupos económicos mais fortes, nos últimos anos (Fidalgo, 2000), o sector continua globalmente muito precário. Há um claro problema de escala, dada a exiguidade do mercado (quer de consumo de media, quer de angariação de publicidade), que faz 
com que uma estrutura mínima de custos fixos, abaixo da qual não é possível descer sobretudo no que toca à quantidade de jornalistas necessários para constituir uma redacção aceitável -, só muito dificilmente seja compensada pelas receitas expectáveis. Assim, a rentabilidade das empresas portuguesas de media acaba sempre por ser muito baixa, ou até negativa em grande parte das situações.

Quando, como sucede no presente, a conjuntura económica pende mais para a recessão do que para a expansão, as "luzes vermelhas" acendem-se de imediato e os despedimentos de jornalistas são a primeira má notícia. Esta precariedade laboral tem, naturalmente, as suas repercussões no exercício profissional, sobretudo nos elos mais frágeis da cadeia produtiva, como são os jovens ou os colaboradores em busca de um emprego estável.

Simultaneamente, crescem as pressões para uma maior produtividade dos jornalistas, seja pondo a tónica mais na quantidade e menos na qualidade da sua produção, seja forçando a utilização gratuita do seu trabalho noutros suportes detidos pelo mesmo grupo, seja obrigando ao alargamento da sua actividade para esferas que pouco têm a ver com o jornalismo e sim com o marketing, com a propaganda, com a promoção comercial, com a infra-estrutura técnica. Esta confusão de papéis, este deliberado esbatimento de fronteiras entre a actividade informativa e os ofícios promocionais, tem repercussões no modo como o público percepciona o trabalho dos jornalistas, aumentando as suas suspeitas sobre aquilo que está a receber e quais as reais motivações que lhe subjazem e reforçando, assim, a crise de credibilidade e de confiança a que aludia no início.

\section{c) $\mathrm{O}$ mercado dos media}

Não é, decerto, exclusiva de Portugal a tendência cada vez mais intensa para olhar e tratar a notícia como mercadoria (Traquina, 2002) - e mercadoria à venda num mercado fortemente concorrencial. De par com esta, e ajudando em alguma medida a compreendê-la, verifica-se outra tendência: a de um grande seguidismo da generalidade dos meios de Comunicação Social relativamente à televisão e às suas lógicas particulares, onde têm lugar de destaque a componente de espectáculo, o predomínio da imagem, a proximidade das emoções das pessoas comuns, o tratamento ligeiro dos assuntos, a passagem rápida ao tema seguinte, as "variedades", em todos os sentidos. Alastra este peculiar "mimetismo mediático" (Ramonet, 1999: 20) que torna os jornais cada vez mais iguais entre si, e todos cada vez mais parecidos com a omnipresente televisão, rapidamente convertida numa espécie de "modelo" (ibid.27) para se avaliar não só o que é ou não é notícia, mas também de que modo deve ser abordado o sucedido para ser notícia.

A perversidade deste circuito fechado acaba por ser ainda maior quando se sabe que a informação televisiva, pelo menos no caso português, é cada vez mais subsidiária das puras lógicas do entretenimento e de boa dose de sensacionalismo ( $h a r d$ ou soft, pouco interessa para o caso), pois a enorme competição pelo escasso bolo publicitário coloca as estações de televisão numa total e absoluta dependência da conquista de audiências. É a tabloidização a infiltrar-se em toda a cena mediática, ainda que com graus diversos.

Neste pano de fundo, um dos patrimónios mais característicos da profissão jornalística e dos mais sensíveis para a assunção das suas responsabilidades no tecido social - o de "valores-notícia" sérios, exigentes e autónomos, como critérios para a 
selecção e desenvolvimento da matéria informativa considerada mais útil e necessária aos cidadãos - acaba por ser subvertido por uma multiplicidade de solicitações e motivações que pouco ou nada têm a ver com jornalismo. Os jornalistas portugueses queixam-se frequentemente de serem empurrados para essas opções mais "comerciais" do que "editoriais" por quem detém o poder nas empresas ou nos media, e de não terem condições de se lhes opor, mesmo quando eventualmente discordam, dadas as fragilidades do sector e a precariedade laboral a que atrás aludi. Sem pôr em causa o argumento, infelizmente muito respeitável, também arriscaria dizer que por vezes o jornalista desiste e aceita demasiado depressa o que vai por tais caminhos, desvalorizando as “áreas de decisão própria” que apesar de tudo tem (Mesquita, 2002: 26), ou cedendo a protagonismos individuais e a fórmulas de sucesso fácil que cativam alguns. A ténue fluidez da sua identidade profissional, que vem de sempre mas que as novas condições do mercado acentuam, ajuda a isso.

\section{d) O grupo profissional}

Atravessado por ambiguidades e dualidades (Rieffel, 2001; Ruellan, 1994), situado numa tensão permanente entre pólos opostos que o reclamam - entre o profissional liberal de consciência e o trabalhador assalariado de facto, entre o criador e o técnico, entre o intelectual e o operário, entre o informador e o propagandista, entre o generalista e o especialista, entre o responsável por um autêntico serviço público e o produtor/ formatador de uma simples mercadoria vendável, entre o feérico show man e o discreto mediador -, o jornalista continua este já longo (embora historicamente ainda breve) caminho na procura de uma melhor definição da sua especificidade, das fronteiras da sua missão própria, dos conhecimentos e competências particulares que lhe são necessários, dos meios mais adequados para atingir os fins que se propõe, e, enfim, de um certo bem-estar consigo mesmo e com o público a quem serve. Ou seja, uma melhor definição da sua identidade, hoje questionada por desafios que, aparentemente, ainda mais desagregam este colectivo profissional do que o congregam.

Tradicionalmente pouco mobilizáveis para reflexões ou acções colectivas, a não ser em alturas de crise evidente, e reconhecendo-se porventura pouco em alguns dos tradicionais instrumentos de representação (como os sindicatos, excessivamente fixados nas questões de índole laboral e contratual estritas, quando não apegados a visões corporativas que os fecham sobre o seu umbigo), os jornalistas portugueses têm sabido lamentar-se muito, desculpar-se bastante, autoflagelar-se quanto baste, mas pouco mais. A este propósito, os movimentos de aproximação que começam a despontar entre o mundo profissional e o mundo académico que estuda estas matérias podem ser um estimulante caminho de análise mais aprofundada dos actuais problemas da profissão, da sua maior abertura à sociedade e da procura de caminhos de renovação. Outros poderão passar por:

- uma mais sistemática e adequada formação profissional, tanto de base como contínua, tanto teórica como prática, tanto nas escolas como nos media, tanto nas especialidades directamente ligadas às Ciências da Comunicação e ao Jornalismo como em áreas que permitam uma mais vasta cultura geral e uma melhor 
compreensão do mundo em que se é chamado a exercer o difícil ofício de informar sem se deixar ingenuamente instrumentalizar ou manipular;

- uma maior exigência e rigor no trabalho quotidiano, um aperfeiçoamento sistemático das competências profissionais, um combate permanente às soluções superficiais ou aos expedientes fáceis, com a certeza de que muitas das falhas até no plano ético de mais não decorrem do que de incompetência, de laxismo ou de falta de empenho nas tarefas de recolha, organização e edição da informação;

- uma maior transparência de processos e uma maior pedagogia junto do público sobre as condições concretas do exercício do jornalismo, informando sobre o próprio processo da informação, contribuindo assim para a formação de leitores/espectadores mais conhecedores das particularidades do sistema mediático, e portanto mais autónomos, mais críticos e mais exigentes quanto ao serviço que lhes é prestado;

- o desenvolvimento de uma mais clara cultura de responsabilidade, individual e colectiva, quanto aos erros e insuficiências do trabalho jornalístico, no pressuposto de que, dando-se corpo ao direito à informação e à liberdade de expressão em nome do público, há que prestar regularmente contas a esse mesmo público, aprendendo também a "saber ouvir" o que ele tem a dizer (Bertrand, 2000: 32) - e não encarar o acesso aos media como um privilégio pessoal de que se usa e abusa a bel-prazer;

- uma maior exigência ética e deontológica, quer no trabalho diário nas redacções, quer no estímulo empenhado à operacionalização de mecanismos autoreguladores - tanto nos próprios media como no plano mais alargado do colectivo profissional (Aznar, 1999) -, de modo a conseguir-se uma fiscalização constante, transparente e eficaz, dos desvios aos códigos de conduta estabelecidos pela e para a profissão, códigos esses que corporizam, afinal o "contrato" (Bernier, 1996: 178) tácito estabelecido com a sociedade e do qual decorre a legitimação do poder associado ao jornalismo. Sem esquecer que o processo de legitimação está permanentemente inacabado, pois "desenrola-se quotidianamente" (ibidem: 190) e só se vai alcançando na justa medida em que cada trabalho concreto respeita os padrões de exigência, de rigor, de transparência e de respeito pela dignidade humana a que os jornalistas, pelo facto de o serem, se comprometem.

\section{Referências bibliográficas}

Aguinava, E. (2001). ‘Dimensión científica del periodismo', in Sala de Prensa, ano III, vol. 2, Janeiro 2001. $<$ http://www.saladeprensa.org/art185.htm>, consultado em 04/10/2002.

Albert, P. (1970). Histoire de la presse, Paris: Presses Universitaires de France.

Aznar, H. (1997). 'El debate sobre la profesionalización del Periodismo: de la titulación a la organización', in ZER-Revista de Estudios de Comunicación, n. ${ }^{\circ}$ 3, Novembro 1997, Bilbao.

Aznar, H. (1999). Comunicación responsable - Deontología y autorregulación de los medios, Barcelona: Ariel Comunicación.

Barbier, J.-M. (dir.) (1996). Savoirs théoriques et savoirs d'action, Paris: Presses Universitaires de France.

Barton, G. (s/d).'What is a journalist?', in Society of Professional Journalists, $<$ http://www.spj.org/quill_issue.asp?ref=306>, consultado em 16/05/02. 
Bernier, M-F. (1996). 'Les conditions de légitimité du journalisme: esquisse d'un modèle théorique', in Les Cahiers du journalisme, n. ${ }^{\circ}$ 2, Dezembro 1996, Lille: Centre de Recherche de l'École Supérieure de Journalisme de Lille.

Bertrand, C.-J. (2000). 'A autonomia do jornalista cresce, se crescer o apoio do público' (entrevista), in Jornalismo e jornalistas, n. ${ }^{\circ} 4$ - Outubro/Dezembro 2000, Lisboa.

Delforce, B. (1996). 'La responsabilité sociale des journalistes: donner du sens', in Les Cahiers du journalisme, n. ${ }^{\circ}$ 2, Dezembro 1996, pp. 16-32, Lille: Centre de Recherche de l’École Supérieure de Journalisme de Lille.

Delporte, C. (1999). Les journalistes en France, 1880-1950 / Naissance et construction d'une profession, Paris: Seuil.

Fidalgo, J. (2000). 'Novos Desafios para a Imprensa Escrita e para o Jornalismo', in Pinto, M. (coord.), (2000). A Comunicação e os Media em Portugal - Cronologia e Leitura de Tendências, Braga: Instituto de Ciências Sociais da Universidade do Minho.

Mathien, M. (1995). Les Journalistes, Paris: Presses Universitaires de France.

Mesquita, M. (2002). 'Envolvimento e distanciamento na conduta do jornalista', in Jornalismo e Jornalistas, n. ${ }^{\circ}$ 10, Abril/Junho 2002, Lisboa.

Neveu, E. (2001). Sociologie du journalisme, Paris: La Découverte.

Ramonet, I. (1999). A Tirania da Comunicação, Porto: Campo das Letras.

Rieffel, R. (2001). Sociologie des médias, Paris: Ellipses.

Ruellan, D.; Lacan, J.-F. \& Palmer, M. (1994). Les Journalistes - Stars, scribes et scribouillards, Paris: Syros.

Ruellan, D. (1997). Les "Pro" du journalisme - De l'état au statut, la construction d'un espace professionnel, Rennes: Presses Universitaires de Rennes.

Traquina, N. (2002). Jornalismo, Lisboa: Quimera.

Ward, S. (2001). 'Window on journalism', in Thunderbirb-UBC Journalism Review,

$<$ http://www.journalism.ubc.ca.thunderbird/2001-02/april/accountability.html>, consultado em 4 de Junho de 2002.

\section{Resumo}

Este artigo aborda algumas das mudanças que se têm verificado no que respeita ao perfil socioprofissional dos jornalistas portugueses nos últimos anos, designadamente no que respeita à idade (jornalistas cada vez mais jovens), ao género (cada vez mais mulheres jornalistas) e à formação académica (cada vez mais jornalistas com formação específica de nível superior). Tentamos perceber até que ponto estas e outras mudanças se reflectem no jornalismo que hoje é feito em Portugal, bem como em que medida elas lançam novos desafios quanto à definição sempre polémica da identidade profissional dos jornalistas.

\section{Abstract}

This article describes and analyzes some of the changes which have ocurred in recent years regarding the social-professional profile of the Portuguese journalists, namely in what concerns age (more and more young journalists), gender (more and more women journalists) and academic formation (more and more journalists with a specific graduate formation). We try to understand to what extent these (and other) changes reflect themselves in the kind of journalism that is being made nowadays in Portugal, as well as in what way they bring new challenges to the traditionally controversial definition of the journalists' professional identity. 